\title{
Tobacco use is not associated with groin hernia repair, a population-based study
}

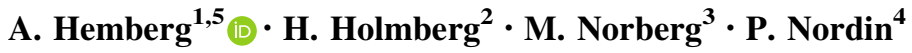

Received: 27 November 2016/ Accepted: 14 April 2017/Published online: 11 May 2017

(c) The Author(s) 2017. This article is an open access publication

\begin{abstract}
Purpose The pathogenesis of groin hernia is not fully understood and some suggested risk factors are debatable. This population-based study evaluates the association between groin hernia repair and tobacco use.

Method An observational study based on register linkage between the Swedish Hernia Register and the Västerbotten Intervention Program (VIP). All primary groin hernia repairs performed from 2001 to 2013 in the county of Västerbotten, Sweden, were included.

Results VIP provided data on the use of tobacco in 102,857 individuals. Neither smoking nor the use of snus, increased the risk for requiring a groin hernia repair. On the contrary, heavy smoking decreased the risk for men, HR 0.75 (95\% CI 0.58-0.96), as did having a BMI over $30 \mathrm{~kg} /$ $\mathrm{m}^{2} \mathrm{HR}$ (men) 0.33 (95\% CI $0.27-0.40$ ).
\end{abstract}

A. Hemberg

hemberg.anders@gmail.com

1 Department of Surgical and Perioperative Sciences, Umeå University, Umeå, Sweden

2 Epidmiology and Global Health Unit, Department of Public Health and Clinical Medicine, Umeå University, Umeå, Sweden

3 Unit of Epidemiology and Global Health, Department of Public Health and Clinical Medicine, Umeå University, Umeå, Sweden

4 Department of Surgical and Perioperative Sciences, Umeå University, Umeå, Sweden

5 Viskgatan 2c, 25247 Helsingborg, Sweden
Conclusion Tobacco use is not a risk factor for requiring a groin hernia repair, whereas having a low BMI significantly increases the risk.

Keywords Hernia · Tobacco · BMI

\section{Introduction}

Previous research has identified family history [1, 2], low BMI [3], abdominal aortic aneurysm [4], patent processus vaginalis [5], abnormal collagen metabolism [6, 7] and certain abdominal operations such as appendectomy and prostatectomy [8], as being risk factors for the development of groin hernia.

There have been speculations regarding tobacco as a possible risk factor $[9,10]$, but until now there has only existed circumstantial evidence of a connection. Furthermore, there is epidemiological evidence indicating that recurrence of hernia is more common $[11,12]$ and that the primary hernia occurs at a younger age [13] among smokers. Others studies have shown that smokers have changes in collagen metabolism $[10,14,15]$ and suggested that there might be a connection with the development of hernia [10]. However, no large-scale research has been performed to see if tobacco use increases the risk for developing a groin hernia.

The aim of this study was to evaluate the correlation between tobacco use and risk for requiring a groin hernia requiring surgical repair. It is based on a register linkage between the Swedish Hernia Register (SHR) [16] and the Västerbotten Intervention Program (VIP) [17]. Tobacco products evaluated are cigarettes and snus, a moist form of oral smokeless tobacco [18].

Our hypothesis was that tobacco use is a risk factor for requiring a groin hernia repair. 


\section{Materials and methods}

\section{The Västerbotten Intervention Program}

The VIP is an ongoing population-based health survey operated by the county of Västerbotten, Sweden. It started as a small pilot study in 1985. From 1990 the program was expanded to include the whole county of Västerbotten in 1992. All citizens are invited to participate at the ages of 40,50 and 60 (until 1995 even 30-year olds were invited) as described in previous reports [17]. Since 2005 participation rates have been 66-67\%. Each year 6500-7000 routine health examinations are included in the register. By 2007 the total number of examinations registered had amounted to 113,203 [17]. An extensive questionnaire constitutes part of the examination, covering amongst other things the use of tobacco [17].

\section{The Swedish Hernia Register}

The SHR started in 1992 and has since grown to include data on over 300,000 groin hernia repairs (GHR). Today, almost all units performing GHR in Sweden are included [19]. Since 2001 all surgical departments in the county of Västerbotten are affiliated. An external review has established that coverage by the SHR of hernia repair surgery performed in Sweden is over 95\% [16].

\section{Study population}

The present cohort study is based on the population registered in the VIP up until January 29, 2013. GHR outcome was added as a variable by register linkage with the SHR. All patients aged fifteen or older with first time GHR performed at any of the surgical units in the county of Västerbotten between January 1, 2001 and December 31, 2013 were included.

It is Swedish law that every permanently residing citizen is assigned a specific identification number used for identification purposes [20]. The SHR has permission to use this number for following up patients and linking their GHR to the unit where it was performed. This identification system was also used for the register linkage of present cohort.

Included individuals were followed till end of 2013, date of GHR or day of death.

The unit of Epidemiology and Global Health at Umeå University provided the service of register linkage and anonymization of data.

\section{Exclusion}

Patients who underwent a GHR before participating in the VIP were excluded. Individuals who exclusively smoked pipe, cigar or pipe and cigar were excluded.

\section{Variables and group definitions}

The definition of groin hernia repair (GHR) in this study included all first time inguinal, femoral and combined repairs. Bilateral hernia surgery was regarded as a single event.

For statistical analyses, the VIP questionnaire on tobacco use was categorized and divided into groups (Text box 1 in appendix). Many worded answers to the questions on tobacco use e.g. "No, never smoked" and "Yes, I smoke occasionally (not daily)" where treated as missing.

BMI values were categorized into three groups, " $<25 \mathrm{~kg} / \mathrm{m}^{2}$ ", " $25-29.9 \mathrm{~kg} / \mathrm{m}^{2}$ ", and " $>30 \mathrm{~kg} / \mathrm{m}^{2}$ ".

Level of education was categorized according to number of years of education, $<9,9-12$, and $>12$ years.

"Age" was age at inclusion in the BIP and was also divided into three groups, $\leq 45,46-55$, and $\geq 55$ years.

Due to the great difference in incidence of groin hernia between men and women all analyses were separated depending on gender.

\section{Statistics}

Independent sample $t$ test was used to compare continuous variables such as time in the study, age and BMI. Chisquare test was used for all categorical variables.

Hazard ratio (HR) was calculated using Cox regression. Confidence intervals $(95 \%)$ are presented with HR in the tables, Wald statistics was used to test statistical significance. For multivariate analyses, the results were stratified for "age at inclusion" since the variable did not satisfy the proportional hazards assumption, this allowed us to adjust for "age at inclusion" while estimating the effects of BMI, education and tobacco.

IBM $^{\circledR}$ SPSS $^{\circledR}$ Statistics Version 22 was used for data management and analyses.

\section{Ethics}

Ethical approval was granted by the Regional Ethics Committee in BLINDED Umeå Sweden.

\section{Results}

This study included a total of 102,857 individuals. After exclusion 100,741 remained for analysis. In the category smoking, 423 were recoded as missing due to answers not being interpretable. A total of 5743 primary GHRs performed in Västerbotten during the study period were registered in the SHR, of which 3080 were also present in the BIP (Fig. 1). 


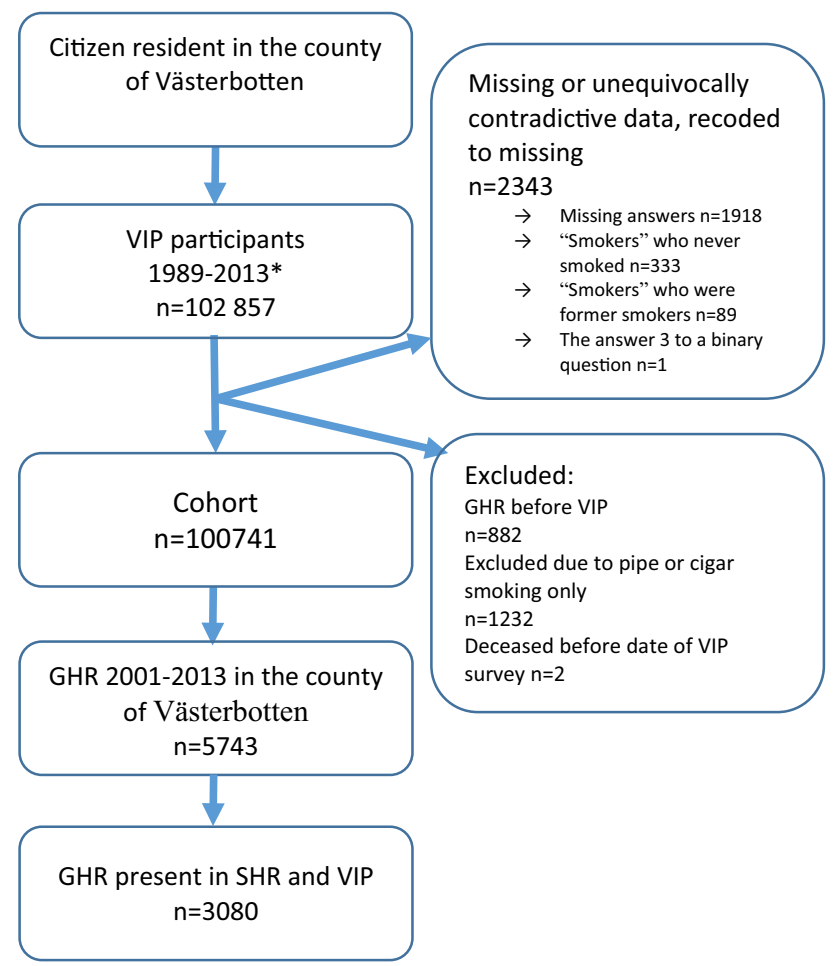

Fig. 1 Flow chart, exclusion and missing data. Flow chart, showing exclusion and cleaning of data. * VIP participants 1989 to January 29, 2013

Basal characteristics showed that there were significant differences between the GHR and none-GHR groups among men with regards to the following variables: smoking, use of snus, BMI, education level, and age at inclusion. Among women, significant differences, between the GHR and non-GHR groups were seen for BMI, education level, and age at inclusion (Table 1).

Univariate analyses for men revealed that heavy smoking and use of snus reduced the HR whereas a BMI $<25$, low education and high age increased the HR. For women, low BMI and high age increased the HR (Table 2).

In the multivariate analyses of the tobacco variables, no significant increased risk amongst tobacco users was seen (Tables 3, 4). On the contrary, in men, heavy smoking significantly lowered the HR (HR 0.75, 95\% CI 0.58-0.96, Table 3), but this was not the case for women. A BMI of 25-29.9 and BMI >30 significantly reduced the $\mathrm{HR}$ in all multivariate analyses in both genders (Tables 3, 4). As regards level of education, 9-12 years of education increased HR significantly for men but not for women in both the smoking and the snus analyses.

\section{Discussion}

\section{Main findings}

Tobacco variables examined in this study did not increase the risk for groin hernia requiring repair, neither in univariate nor in multivariate analysis.

The variable found to have greatest impact on risk for GHR was a BMI $>25 \mathrm{~kg} / \mathrm{m}^{2}$ that significantly decreased risk in all analyses, in both genders.

\section{Strengths}

The main strength of this study was the size of the study population. Extensive exposure data on BMI, tobacco use and educations level where collected from 102,857 individuals. The longitudinal approach of a cohort study adds strength.

The $>95 \%$ coverage of the SHR database is itself a considerable strength [16].

The fact that high exposure groups were used when investigating the effect of smoking and the use of snus, adds reliability to the conclusion that tobacco use does not increase the risk of GHR.

\section{Limitations}

Information on the use of tobacco only accounts for the amount consumed at one point in time, there is no continuous follow-up. For this reason, changes in tobacco consumption over time cannot be accounted for. The time from when the information was provided at inclusion to event or the end of the study varies from a few days to 22.8 years.

Since VIP data are based on questionnaires, there is room for subjective assessment. Questionnaires have other drawbacks since some responders might not answer all the questions or provide missing or unequivocally contradictive data.

The VIP is an intervention program and participants receive health counseling based on their answers. This could have an effect on our analyses as some individuals may have changed their habits during the survey.

The VIP program has three inclusion ages (40, 50 and 60) while the SHR includes all GHRs occurring from the age of fifteen. Consequently, some patients had undergone GHR before inclusion in the VIP survey, and were thus excluded from the study.

Participation in the VIP and SHR is voluntary, thus risking selection bias in the study population. The good coverage of the SHR minimizes this risk. The VIP has a coverage of $66-67 \%$ somewhat limiting the basis of this cohort. However, only slight social selection bias was reported [21]. There is an underestimation of the incidence of GHR in present study since the total VIP cohort since 1989 was used. The first year SHR 
Table 1 Baseline characteristics from the Västerbotten Intervention Program cohort between 1989 and 2013 with 3080 groin hernia repairs added from Swedish Hernia Register

\begin{tabular}{|c|c|c|c|c|c|c|c|c|}
\hline & \multicolumn{4}{|c|}{ Men $n=48,662$} & \multicolumn{4}{|c|}{ Women $n=52,079$} \\
\hline & $\begin{array}{l}\text { None-GHR } \\
n(\%)\end{array}$ & $\begin{array}{l}\text { GHR } \\
n(\%)\end{array}$ & $\begin{array}{l}\text { Total } \\
n(\%)\end{array}$ & $p$ & $\begin{array}{l}\text { None-GHR } \\
n(\%)\end{array}$ & $\begin{array}{l}\text { GHR } \\
n(\%)\end{array}$ & $\begin{array}{l}\text { Total } \\
n(\%)\end{array}$ & $p$ \\
\hline \multicolumn{9}{|l|}{ Smoking } \\
\hline Never smoked & $23,221(51.2)$ & $912(47.7)$ & $24,133(51.1)$ & \multirow[t]{4}{*}{0.001} & $25,933(50.9)$ & $78(49.4)$ & $26,011(50.9)$ & \multirow[t]{4}{*}{0.305} \\
\hline Previous use & $14,972(33.0)$ & $718(37.5)$ & $15,690(33.2)$ & & $15,605(30.6)$ & $42(26.6)$ & $15,647(30.6)$ & \\
\hline Light smoker & 5238 (11.6) & $211(11.0)$ & 5449 (11.5) & & 7839 (15.4) & $32(20.3)$ & $7871(15.4)$ & \\
\hline Heavy smoker & $1911(4.2)$ & $72(3.8)$ & $1983(4.2)$ & & $1555(3.1)$ & $6(3.8)$ & $1561(3.1)$ & \\
\hline \multicolumn{9}{|l|}{ Snus } \\
\hline Never used & $25,802(56.8)$ & $1212(63.2)$ & $27,014(57)$ & \multirow[t]{4}{*}{$<0.001$} & $44,010(87.8)$ & $145(94.8)$ & $44,155(87.8)$ & \multirow[t]{4}{*}{0.069} \\
\hline Previous use & 7835 (17.2) & $308(16.1)$ & 8143 (17.2) & & $2500(5.0)$ & $4(2.6)$ & $2504(5.0)$ & \\
\hline Light use & $8522(18.7)$ & $314(16.4)$ & 8836 (18.7) & & $2840(5.7)$ & $3(2.0)$ & $2843(5.7)$ & \\
\hline Heavy use & $3294(7.2)$ & $83(4.3)$ & $3377(7.1)$ & & $792(1.6)$ & $1(0.7)$ & $793(1.6)$ & \\
\hline \multicolumn{9}{|l|}{ BMI } \\
\hline $\mathrm{BMI}<25$ & $14,886(32.6)$ & $846(43.8)$ & $15,732(33)$ & \multirow[t]{3}{*}{$<0.001$} & $24,511(48.1)$ & $97(60.2)$ & $24,608(48.1)$ & \multirow[t]{3}{*}{0.008} \\
\hline BMI 25-29.9 & $22,597(49.4)$ & $960(49.7)$ & $23,557(49.5)$ & & $17,369(34.1)$ & $44(27.3)$ & $17,413(34.1)$ & \\
\hline $\mathrm{BMI} \geq 30$ & $8221(18.0)$ & $124(6.4)$ & 8345 (17.5) & & $9092(17.8)$ & $20(12.4)$ & $9112(17.8)$ & \\
\hline \multicolumn{9}{|l|}{ Education } \\
\hline $0-9$ years & $11,460(24.8)$ & $728(37.1)$ & $12,188(25.3)$ & \multirow[t]{3}{*}{$<0.001$} & $13,366(26.0)$ & $68(41.7)$ & $13,434(26.1)$ & \multirow[t]{3}{*}{$<0.001$} \\
\hline $9-12$ years & $23,473(50.7)$ & 841 (42.9) & $24,314(50.4)$ & & $20,883(40.7)$ & $58(35.6)$ & $20,941(40.7)$ & \\
\hline$>12$ years & $11,324(24.5)$ & $392(20.0)$ & $11,716(24.3)$ & & $17,089(33.3)$ & 37 (22.7) & $17,126(33.3)$ & \\
\hline \multicolumn{9}{|l|}{ Age at inclusion } \\
\hline$<45$ & $14,575(31.2)$ & $273(13.8)$ & $14,848(30.5)$ & \multirow[t]{3}{*}{$<0.001$} & $15,131(29.1)$ & $22(13.4)$ & $15,153(29.1)$ & \multirow[t]{3}{*}{$<0.001$} \\
\hline $46-55$ & $13,210(28.3)$ & 409 (20.7) & $13,619(28.0)$ & & $14,418(27.8)$ & $27(16.5)$ & $14,445(27.7)$ & \\
\hline $56-65$ & $18,899(40.5)$ & $1296(65.5)$ & $20,195(41.5)$ & & $22,366(43.1)$ & $115(70.1)$ & $22,481(43.2)$ & \\
\hline
\end{tabular}

The Västerbotten Intervention Program cohort between 1989 and 2013 with 3080 groin hernia repairs added from Swedish Hernia Register. $p$ Values are Chi-Square tests, used to examine differences within each group

that included all GHRs in the county of Västerbotten was 2001, so only GHR after that year were included. We have no reason to suspect that there was a difference in risk factors for developing a groin hernia in need of repair before or after 2001 .

Another aspect worth considering is that both heavy smoking and high BMI may have influenced surgeons and anesthesiologists in their risk-benefit calculation before deciding whether or not to perform a GHR. There is a possibility that this might have reduced the number of hernias considered suitable for operation in the heavy smoking and high BMI groups. Previous research has concluded that elective day-case surgery is associated with reduced risk for complications compared to emergency surgery [22], increasing the indication for elective day-case surgery on patients with several risk factors.

This study is based on hernia requiring repair and not the presence of groin hernia. Consequently, risk factors for developing a groin hernia requiring surgery are not necessarily the same as risk factors for actual formation of groin hernia. As with all observational studies, correlation is not necessarily the same as causation.

\section{Relation to current knowledge}

In this study, tobacco use did not increase the HR for GHR. We could only find two studies indicating an increased risk for hernia among smokers. In one of these, serum pancreas elastase activity was found to be increased among smokers with a direct or indirect hernia, and tobacco use was mentioned as a possible risk factor [10]. An observational cohort including 75 patients found earlier onset of primary hernia among smokers [13], indicating an association.

This study showed that individuals who smoke heavily had a decreased HR for undergoing a groin hernia repair, whereas other smaller case-control studies examining risk factors among men [1, 23, 24], women [25], and both genders [26] have failed to show any significant effect of smoking. There are, however, two studies with results that correlate with ours. One reported a close to significant decrease in hazard ratio $(0.82,95 \%$ CI $0.65-1)$ among current smokers [27], and another reported a significantly decreased hazard ratio among individuals who smoked more than fifteen grams of tobacco each day [28]. 
Table 2 Univariate Cox regression analyses for requiring a groin hernia repair

\begin{tabular}{|c|c|c|c|c|}
\hline & \multicolumn{2}{|l|}{ Men } & \multicolumn{2}{|l|}{ Women } \\
\hline & $\operatorname{HR}(95 \% \mathrm{CI})$ & $p$ & $\mathrm{HR}(95 \% \mathrm{CI})$ & $p$ \\
\hline \multicolumn{5}{|l|}{ Smoking } \\
\hline Never smoked & 1.00 & & 1.00 & \\
\hline Previous use & $1.09(0.99-1.20)$ & 0.08 & $0.97(0.66-1.41)$ & 0.86 \\
\hline Light smoker & $0.91(0.78-1.05)$ & 0.19 & $1.22(0.81-1.84)$ & 0.35 \\
\hline Heavy smoker & $0.71(0.56-0.91)$ & 0.01 & $1.01(0.44-2.31)$ & 0.99 \\
\hline \multicolumn{5}{|l|}{ Snus } \\
\hline Never used & 1.00 & & 1.00 & \\
\hline Previous use & $0.99(0.87-1.12)$ & 0.84 & $0.74(0.27-2.01)$ & 0.56 \\
\hline Light use & $0.85(0.75-0.96)$ & 0.01 & $0.45(0.14-1.42)$ & 0.17 \\
\hline Heavy use & $0.69(0.55-0.86)$ & $<0.01$ & $0.70(0.10-4.99)$ & 0.72 \\
\hline \multicolumn{5}{|l|}{ BMI } \\
\hline$<25$ & 1.00 & & 1.00 & \\
\hline $25-29.9$ & $0.80(0.73-0.88)$ & $<0.01$ & $0.63(0.44-0.89)$ & 0.01 \\
\hline$\geq 30$ & $0.33(0.27-0.4)$ & $<0.01$ & $0.59(0.36-0.95)$ & 0.03 \\
\hline \multicolumn{5}{|l|}{ Education } \\
\hline $0-9$ years & 1.00 & & 1.00 & \\
\hline $9-12$ years & $0.83(0.75-0.92)$ & $<0.01$ & $0.84(0.59-1.2)$ & 0.35 \\
\hline$>12$ years & $0.80(0.71-0.91)$ & $<0.01$ & $0.71(0.47-1.06)$ & 0.09 \\
\hline \multicolumn{5}{|l|}{ Age at inclusion } \\
\hline$<45$ & 1.00 & & 1.00 & \\
\hline $46-55$ & $1.87(1.60-2.17)$ & $<0.01$ & $1.44(0.82-2.53)$ & 0.20 \\
\hline $56-65$ & $3.19(2.80-3.63)$ & $<0.01$ & $2.88(1.82-4.54)$ & $<0.01$ \\
\hline
\end{tabular}

Univariate analyses using Cox regression to calculate hazard ratio (HR) and $p$ values. $p$ values are Wald$p$. Based on the Västerbotten Intervention Program cohort between 1989 and 2013 with 3080 groin hernia repairs added from Swedish Hernia Register

\begin{tabular}{|c|c|c|c|c|}
\hline & \multicolumn{2}{|l|}{ Men } & \multicolumn{2}{|l|}{ Women } \\
\hline & $\mathrm{HR}(95 \% \mathrm{CI})$ & $p$ & $\mathrm{HR}(95 \% \mathrm{CI})$ & $p$ \\
\hline \multicolumn{5}{|l|}{ Smoking } \\
\hline Never smoked & 1.00 & & 1.00 & \\
\hline Previous use & $0.97(0.87-1.07)$ & 0.54 & $1.13(0.76-1.68)$ & 0.54 \\
\hline Light smoker & $0.92(0.79-1.08)$ & 0.32 & $1.25(0.79-1.98)$ & 0.35 \\
\hline Heavy smoker & $0.75(0.58-0.96)$ & 0.03 & $1.22(0.49-3.05)$ & 0.67 \\
\hline \multicolumn{5}{|l|}{ BMI } \\
\hline$<25$ & 1.00 & & 1.00 & \\
\hline $25-29.9$ & $0.72(0.65-0.79)$ & $<0.01$ & $0.56(0.38-0.83)$ & 0.01 \\
\hline$\geq 30$ & $0.33(0.27-0.40)$ & $<0.01$ & $0.52(0.31-0.88)$ & 0.02 \\
\hline \multicolumn{5}{|l|}{ Education } \\
\hline Education $0-9$ years & 1.00 & & 1.00 & \\
\hline Education 9-12 years & $1.16(1.03-1.29)$ & 0.01 & $1.18(0.79-1.78)$ & 0.42 \\
\hline Education $>12$ years & $1.03(0.90-1.18)$ & 0.67 & $0.95(0.60-1.51)$ & 0.83 \\
\hline
\end{tabular}

Multivariate analyses with focus on smoking, based on the 100,741 individuals in the Västerbotten Intervention Program cohort between 1989 and 2013 with 3080 groin hernia repairs added from Swedish Hernia Register Hazard ratio (HR) calculated by Cox regression adjusted for all variables in the table, stratified for age at inclusion. $p$ values are Wald- $p$ 
Table 4 Multivariate Cox regression analyses focued on snus

\begin{tabular}{|c|c|c|c|c|}
\hline & \multicolumn{2}{|l|}{ Men } & \multicolumn{2}{|l|}{ Women } \\
\hline & $\mathrm{HR}(95 \% \mathrm{CI})$ & $p$ & $\operatorname{HR}(95 \% \mathrm{CI})$ & $p$ \\
\hline \multicolumn{5}{|l|}{ Snus } \\
\hline Never used & 1.00 & & 1.00 & \\
\hline Previous use & $1.10(0.96-1.25)$ & 0.17 & $1.33(0.48-3.72)$ & 0.58 \\
\hline Light use & $0.93(0.82-1.07)$ & 0.31 & $0.74(0.23-2.36)$ & 0.61 \\
\hline Heavy use & $1.04(0.82-1.32)$ & 0.72 & $1.22(0.17-8.94)$ & 0.84 \\
\hline \multicolumn{5}{|l|}{ BMI } \\
\hline$<25$ & 1.00 & & 1.00 & \\
\hline $25-29.9$ & $0.71(0.65-0.79)$ & $<0.01$ & $0.56(0.38-0.82)$ & 0.01 \\
\hline$\geq 30$ & $0.33(0.27-0.40)$ & $<0.01$ & $0.51(0.30-0.87)$ & 0.01 \\
\hline \multicolumn{5}{|l|}{ Education } \\
\hline Education $0-9$ years & 1.00 & & 1.00 & \\
\hline Education 9-12 years & $1.16(1.04-1.30)$ & 0.01 & $1.18(0.79-1.77)$ & 0.42 \\
\hline Education $>12$ years & $1.04(0.91-1.19)$ & 0.54 & $0.93(0.59-1.47)$ & 0.75 \\
\hline
\end{tabular}

Multivariate analyses with focus on snus, based on the 100,741 individuals in the Västerbotten Intervention Program cohort between 1989 and 2013 with 3080 groin hernia repairs added from Swedish Hernia Register Hazard Ratio (HR) calculated by Cox regression adjusted for all variables in the table, stratified for age at inclusion. $p$ values are Wald- $p$
Since the use of snus is uncommon outside Scandinavia, no other studies on its effect on hernia formation exist to our knowledge.

In the present cohort high BMI was a protective factor against developing a groin hernia requiring surgery. This finding correlates well with the results of previous trials $[3,25,27,28]$.

\section{Conclusion}

Tobacco use is not a risk factor for requiring a groin hernia repair. A high BMI is associated with lower risk, though more extensive analysis is required to confirm this.

\section{Compliance with ethical standards}

Conflicts of interest The authors have been declares no conflict of interest.

Funding The study was financially supported by the SHR that is exclusively funded by the Swedish government. There was no other source of funding.

Ethical statement Present study was aproved by the Regional Ethics Committee in Umeå Sweden.

Statement on human rights For this type of study, formal consent is not required.

Statement on the welfare of animals This article does not contain any studies with animals performed by any of the authors.

Informed consent Informed consent was obtained from all individuals at participation in VIP and SHR. This study has been performed in accordance with Swedish law.
Open Access This article is distributed under the terms of the Creative Commons Attribution-NonCommercial 4.0 International License (http://creativecommons.org/licenses/by-nc/4.0/), which permits any noncommercial use, distribution, and reproduction in any medium, provided you give appropriate credit to the original author(s) and the source, provide a link to the Creative Commons license, and indicate if changes were made.

\section{Appendix}

See the Text box 1 in appendix.

Text box 1 Tobacco use grouping

\begin{tabular}{ll}
\hline & Categorized as \\
\hline VIP question: "Do you smoke?" & \\
(A) No, never smoked & Never smoked \\
(B) Not now, but smoked regularly before & Previous use \\
(C) Not now, but have smoked now and again & Previous use \\
(D) Yes, I smoke occasionally (not daily) & Light smoker \\
(E) Yes, I smoke cigarettes 1-4 each day & Light smoker \\
(F) Yes, I smoke cigarettes 5-14 each day & Light smoker \\
(G) Yes, I smoke cigarettes 15-24 each day & Heavy smoker \\
(H) Yes, I smoke cigarettes 25 or more each day & Heavy smoker \\
VIP question: "Have you ever used snus? & \\
1. No & Never used \\
2. Yes, I used to do it, but not anymore & Previous use \\
3. Yes, I use less than 2 boxes each week & Light use \\
4. Yes, I use 2-4 boxes each week & Light use \\
5. Yes, I use more than 4 but less than 7 boxes each & Heavy use \\
week & \\
6. Yes, I use 7 boxes or more each week & Heavy use \\
\hline
\end{tabular}

VIP questions above are translated from Swedish to English. The answer "yes" was added to each group 


\section{References}

1. Lau H, Fang C, Yuen WK, Patil NG (2007) Risk factors for inguinal hernia in adult males: a case-control study. Surgery 141:262-266. doi:10.1016/j.surg.2006.04.014

2. Carbonell JF, Sanchez JL, Peris RT et al (1993) Risk factors associated with inguinal hernias: a case control study. Eur J Surg 159:481-486

3. Zendejas B, Hernandez-Irizarry R, Ramirez T et al (2014) Relationship between body mass index and the incidence of inguinal hernia repairs: a population-based study in Olmsted County. MN Hernia 18:283-288. doi:10.1007/s10029-013-11855

4. Lehnert B, Wadouh F (1992) High coincidence of inguinal hernias and abdominal aortic aneurysms. Ann Vasc Surg 6:134-137

5. van Veen RN, van Wessem KJ, Halm JA et al (2007) Patent processus vaginalis in the adult as a risk factor for the occurrence of indirect inguinal hernia. Surg Endosc 21:202-205. doi:10. 1007/s00464-006-0012-9

6. Klinge U, Zheng H, Si ZY, Schumpelick V, Bhardwaj R, Klosterhalfen B (1999) Synthesis of type I and III collagen, expression of fibronectin and matrix metalloproteinases-1 and -13 in hernial sac of patients with inguinal hernia. Int J Surg Investig 1:219-227

7. Burcharth J, Rosenberg J (2008) Hernias as medical disease. Ugeskr Laeger 170:3314-3318

8. Abe T, Shinohara N, Harabayashi T et al (2007) Postoperative inguinal hernia after radical prostatectomy for prostate cancer. Urology 69:326-329

9. Simons MP, Aufenacker T, Bay-Nielsen M et al (2009) European Hernia Society guidelines on the treatment of inguinal hernia in adult patients. Hernia 13:343-403. doi:10.1007/s10029-0090529-7

10. Cannon DJ, Read RC (1981) Metastatic emphysema: a mechanism for acquiring inguinal herniation. Ann Surg 194:270-278

11. Sorensen LT, Friis E, Jorgensen T et al (2002) Smoking is a risk factor for recurrence of groin hernia. World J Surg 26:397-400. doi:10.1007/s00268-001-0238-6

12. Burcharth J, Pommergaard HC, Bisgaard T, Rosenberg J (2014) Patient-related risk factors for recurrence after inguinal hernia repair: a systematic review and meta-analysis of observational studies. Surg Innov. doi:10.1177/1553350614552731

13. Jansen PL, Klinge U, Jansen M, Junge K (2009) Risk factors for early recurrence after inguinal hernia repair. BMC Surg 9:18. doi:10.1186/1471-2482-9-18

14. Jorgensen LN, Kallehave F, Christensen E, Siana JE, Gottrup F (1998) Less collagen production in smokers Surgery 123:450-455
15. Norman PE, Curci JA (2013) Understanding the effects of tobacco smoke on the pathogenesis of aortic aneurysm. Arterioscler Thromb Vasc Biol 33:1473-1477. doi:10.1161/ATV BAHA. 112.300158

16. Haapaniemi SA (2001) Swedish thesis on groin hernia surgery. Hernia 5:204-205

17. Norberg M, Wall S, Boman K, Weinehall L (2010) The Västerbotten intervention programme: background, design and implications. Glob Health Action 22:3. doi:10.3402/gha.v3i0.4643

18. Burris JL, Wahlquist AE, Alberg AJ et al (2016) A longitudinal, naturalistic study of U.S. smokers' trial and adoption of snus. Addict Behav 63:82-88. doi:10.1016/j.addbeh.2016.07.008

19. The Swedish Hernia Register (SHR) www.svensktbrackregister. se. Accessed 10 Nov 2016

20. Ludvigsson JF, Otterblad-Olausson P, Pettersson BU, Ekbom A (2009) The Swedish personal identity number: possibilities and pitfalls in healthcare and medical research. Eur J Epidemiol 24:659-667. doi:10.1007/s10654-009-9350-y

21. Norberg M, Blomstedt Y, Lönnberg G et al (2012) Community participation and sustainability-evidence over 25 years in the Västerbotten Intervention Programme. Glob Health Action 5:1-9

22. Nilsson H, Stylianidis G, Haapamäki M, Nilsson E, Nordin P (2007) Mortality after groin hernia surgery. Ann Surg 245:656-660. doi:10.1097/01.sla.0000251364.32698.4b

23. Ashindoitiang JA, Ibrahim NA, Akinlolu OO (2012) Risk factors for inguinal hernia in adult male Nigerians: a case control study. Int J Surg 10:364-367. doi:10.1016/j.ijsu.2012.05.016

24. de Goede B, Timmermans L, van Kempen BJ et al (2015) Risk factors for inguinal hernia in middle-aged and elderly men: results from the Rotterdam Study. Surgery 157:540-546. doi:10. 1016/j.surg.2014.09.029

25. Liem MS, van der Graaf Y, Zwart RC, Geurts I, van Vroonhoven TJ (1997) Risk factors for inguinal hernia in women: a casecontrol study. The Coala Trial Group Am J Epidemiol 146:721-726

26. Flich J, Alfonso JL, Delgado F, Prado MJ, Cortina P (1992) Inguinal hernia and certain risk factors. Eur $\mathrm{J}$ Epidemiol 8:277-282

27. Ruhl CE, Everhart JE (2007) Risk factors for inguinal hernia among adults in the US population. Am J Epidemiol 165:1154-1161. doi:10.1093/aje/kwm011

28. Rosemar A, Angerås U, Rosengren A (2008) Body mass index and groin hernia: a 34-year follow-up study in Swedish men. Ann Surg 247:1064-1068. doi:10.1097/SLA.0b013e31816b4399 